\title{
Projeto Integrado de Prática Educativa: uma experiência no curso de matemática
}

\author{
Fabiana Fiorezi de Marco* \\ Maria Teresa Menezes Freitas** \\ Anna Regina Lanner de Moura***
}

\begin{abstract}
Resumo
Este artigo discute uma proposta de trabalho desenvolvida em uma pesquisa realizada no Projeto Integrado de Prática Educativa - PIPE - da Faculdade de Matemática da Universidade Federal de Uberlândia. Foram selecionados para a pesquisa os registros de dezesseis licenciandos da disciplina, "Informática e Ensino" do Curso de Matemática da Universidade. Da análise das elaborações e reflexões dos licenciandos, ocorridas durante o desenvolvimento das aulas e registradas, tanto por escrito quanto em áudio, evidenciou-se a importância do envolvimento do professor responsável pelo componente curricular integrado ao PIPE, tendo em vista a necessidade de planejamento detalhado e específico das dinâmicas que devem ser realizadas nos momentos não presenciais do componente.

Palavras-chave: Formação de professores de Matemática; Projeto Integrado de Prática Educativa; Tecnologia Computacional.
\end{abstract}

\section{Integrated Project of Educative Practice: an experience in a Mathematis Course}

\begin{abstract}
This paper focus attention in a formative intervention work developed in the circuit of a subject called "Informatics and Teaching" part of an Integrated Project of Educative practice - PIPE -of the Mathematics Faculty of the Federal University of Uberlândia. It was selected for the research written records of sixteen future teachers of the Mathematics Course of the University. The analysis of the written elaborated records and the reflections of the participants that occurred during the development of the teaching classes and registered, not only in written format, but also in audio tape recorder, made evident the importance of the involvement of the professor responsible for the curricular component attached to PIPE, due to the necessity of a specific and detailed planning of the dynamics that should be realized in moments not present that were part of the curricular component.

Keywords: Mathematics teacher formation; Integrated Project of Educative Practice; Computation Technology.
\end{abstract}

\section{Introdução}

Este artigo refere-se ao papel do componente curricular Projeto Integrado de Prática Educativa - PIPE - incluído em disciplinas do curso de Matemática da Universidade Federal de Uberlândia - UFU. O tema se insere nos grandes debates sobre formação docente e, particularmente, da formação do professor de matemática.

$\mathrm{Na}$ proposta do Projeto Pedagógico do Curso de Licenciatura em Matemática da UFU identificamos

[...] uma estrutura curricular organizada em 8 períodos semestrais, composto por 30 disciplinas obrigatórias e um elenco variado de 20 disciplinas optativas. Para a integralização do Curso o aluno deverá cumprir uma carga horária de 2.130 horasaula em conteúdos de natureza científico-

* Endereço eletrônico: ffmarco@gmail.com

** Endereço eletrônico: mtmfreitas@gmail.com

*** Endereço eletrônico: lanner4@gmail.com cultural, 405 horas-aula em Prática como componente curricular, 410 horas de estágio supervisionado, 200 horas de atividades científico-culturais complementares, num total de 3.145 horas, em período integral, durante quatro anos. Desse total, 2765 horas são de componentes obrigatórios e 380 de componentes de escolha do aluno (p.14, 2005).

Ainda, nesta proposta, verifica-se que os componentes curriculares estão dispostos em núcleos denominados: Núcleo de Formação Específica, Núcleo de Formação Pedagógica e Núcleo de Formação Acadêmico - Científico Cultural.

Embora os dois núcleos se apresentem articulados na proposta percebe-se que a articulação almejada dependerá da atuação dos professores responsáveis pelas disciplinas para dar o movimento 
que a interdisciplinaridade e a relação teoria-prática exigem.

Os componentes do Núcleo de Formação Pedagógica estão divididos em três partes: Disciplinas de Formação Pedagógica, Práticas Específicas e Estágio Supervisionado. Na compreensão do componente denominado "Práticas Específicas", o texto do Projeto Pedagógico do curso explicita que

[...] em nível institucional, a Resolução 03/2005 do Conselho Universitário instituiu, no âmbito da dimensão prática, a existência do Projeto Integrado de Prática Educativa (PIPE), que buscará desenvolver ao longo do curso de formação de professores, atividades teóricas-práticas que articulem as disciplinas de formação específica e pedagógica, assumindo, portanto, um caráter coletivo $e$ interdisciplinar. Ao mesmo será destinada uma carga horária correspondente e este culminará no Seminário de Prática Educativa (SPE), cujos processos de elaboração, desenvolvimento e avaliação do PIPE / SPE serão coordenados pelo Colegiado de Curso (p.17, 2005).

Assim, no intuito de alcançar uma plena articulação entre teoria e prática a proposta propõe uma interação diluída nas disciplinas de formação específica e pedagógica, estabelecendo uma divisão de ações a serem desenvolvidas no PIPE denominadas por:

- PIPE 1: "Contextualização Sócio-Cultural”;

- PIPE 2: "Novos Temas no Currículo do Ensino Básico";

- PIPE 3: "Investigação e Compreensão";

- PIPE 4 "Temas e Questões Educacionais Transversais".

Em termos de carga-horária e localização na estrutura curricular temos:

\begin{tabular}{|c|c|c|c|c|}
\hline \multirow[b]{2}{*}{ PIPE } & \multirow[b]{2}{*}{ DISCIPLINAS AGREGADAS AO PIPE } & \multicolumn{3}{|c|}{ CARGA HORÁRIA } \\
\hline & & $\begin{array}{c}\text { PRESENCIA } \\
\text { L }\end{array}$ & $\begin{array}{c}\text { NÃO } \\
\text { PRESENCIA } \\
\text { L }\end{array}$ & TOTAL \\
\hline PIPE 1 & - Introdução a Matemática ( $1^{\circ}$ Período - 45h) & 45 & 0 & 45 \\
\hline PIPE 2 & $\begin{array}{l}\text { - Informática e Ensino }\left(2^{\circ} \text { Período }-30 \mathrm{~h}\right) \\
\text { - Matemática Finita }\left(3^{\circ} \text { Período }-15 \mathrm{~h}\right) \\
\text { - Estatística e Probabilidade }\left(4^{\circ} \text { Período }-15 \mathrm{~h}\right)\end{array}$ & 0 & 60 & 60 \\
\hline PIPE 3 & $\begin{array}{l}\text { - Geometria Euclidiana Espacial }\left(3^{\circ} \text { Período }-15 \mathrm{~h}\right) \\
\text { - Ensino de Matemática através de Problemas }\left(6^{\circ}\right. \\
\text { Período }-30 \mathrm{~h})\end{array}$ & 0 & 45 & 45 \\
\hline PIPE 4 & $\begin{array}{l}\left.\text { - Psicologia da Educação ( } 5^{\circ} \text { Período }-15 \mathrm{~h}\right) \\
\text { - Política e Gestão da Ed. (5 Período - } 15 \mathrm{~h}) \\
\text { - Didática Geral }\left(6^{\circ} \text { Período }-15 \mathrm{~h}\right)\end{array}$ & 0 & 45 & 45 \\
\hline & TOTAIS & 45 & 150 & 195 \\
\hline
\end{tabular}

Quadro 1 - Distribuição e Carga-horária do PIPE ao longo do curso Fonte: Projeto Pedagógico do Curso de Matemática

Vale novamente destacar que o envolvimento do professor responsável por cada componente é fundamental, em especial, pela proposta envolver momentos não presenciais que exigem dinâmicas e planejamentos detalhados e específicos. Entretanto, há de se admitir que embora ousada a proposta traz em si possibilidades de contribuições inestimáveis para a formação do futuro professor de matemática, como discutido neste artigo.

Em relação ao envolvimento do professor no planejamento de tais componentes, percebeu-se a necessidade de garantir o interesse dos alunos apresentando propostas que gerem motivos para aprender e para dedicar-se. Surge então uma questão inquietante: Como concretizar esta realidade?

Para ilustrar esta possibilidade apresentamos a proposta desenvolvida no âmbito do componente denominado Projeto Integrado de Prática Educativa (PIPE) ${ }^{1}$, na disciplina Informática e Ensino do Curso de Matemática da Universidade Federal de Uberlândia. O estudo teve como foco 
discutir como o futuro professor de matemática pode utilizar ambientes computacionais para produzir atividades de ensino que possam desencadear e desenvolver, em seu futuro aluno, uma possibilidade de pensar conceitos matemáticos de modo significativo.

Esse contexto de formação, assim constituído, reitera as ideias de Cardim (2008) sobre a necessidade de proporcionar "experiências durante a formação inicial do professor que dêem condições para a (re)significação de bases pedagógicas, contribuindo para a constituição profissional do educador" (p.8). Outro aspecto a ser considerado nesse contexto é o fato de ser possibilitado ao estudante a experiência de o saber ser "fruto da interação entre sujeitos, o fruto de uma interação lingüística inserida num contexto" (GAUTHIER, 2006, p.339) e de ser ouvido, de modo a se tornar co-participante, co-responsável por sua formação e pela formação dos colegas da disciplina.

\section{A formação inicial de professores de matemática}

A formação inicial de professores tem sido alvo de estudos de várias pesquisas nacionais e internacionais ${ }^{2}$. Marcelo Garcia (1999) considera a formação de professores como um campo téoricoprático e uma área de conhecimentos e de investigação voltada ao desenvolvimento do ensino e do currículo escolar, visando à melhoria da qualidade educativa dos alunos.

Salienta-se a importância de se possibilitar aos alunos no processo de formação para a docência o desenvolvimento de capacidades "em que os conteúdos curriculares não atuam como fins em si mesmos, mas como meios para a aquisição e desenvolvimento dessas capacidades" tendo em vista "que o aluno possa ser sujeito de sua própria formação, em um complexo processo interativo em que também o professor se veja como sujeito de conhecimento." (BRASIL, 1997, p.44).

Diante destas premissas e com fundamentação em Cardim (2008), parece ser imprescindível que em programas de formação docente haja espaços de formação que permitam aos futuros professores (re)pensar concepções sobre a matemática e seu ensino, tecendo reflexões que possam fundamentar as práticas que irão influenciar na constituição do professor de matemática.

Reitera-se que neste estudo, apresentado como possibilidade na formação do professor, o foco de interesse centra-se na formação inicial do professor de matemática e na utilização da tecnologia computacional nessa formação, como parte do Projeto Integrado de Prática Pedagógica na disciplina Informática e Ensino,

[...] visto que esta tecnologia está presente direta ou indiretamente no contexto social do cidadão do século XXI, e deve ser vista não mais como uma tendência na educação, mas sim como uma realidade que cria um ambiente cultural educativo capaz de promover um meio de diversificar o conhecimento em todas as dimensões do ensino, inclusive do saber matemático (CARDIM, 2008, p.32).

Outros pesquisadores ${ }^{3}$ também direcionam seus olhares para a questão da tecnologia na formação docente. Para Lanner de Moura, Miskulin e Melo (2000), a formação inicial docente constitui

[...] uma das instâncias onde a utilização do computador como ferramenta pode contribuir para a construção de uma nova cultura profissional. Uma construção que integre a ferramenta à atividade humana do professor, bem como os saberes tecnológicos oriundos de uma ação construtiva do professor sobre a máquina (p.151).

Silva e Fernandes (2007) acreditam ser de importância essencial trazer esta discussão para cursos de formação de professores destacando dois motivos: o primeiro concretiza-se pela "necessidade de a universidade estar em sintonia com os alunos dos cursos de licenciatura, na maioria dos casos, jovens que já se encontram imersos nesse campo tecnológico" (p.63); o segundo, pelo fato de que "num curto espaço de tempo, esses mesmos alunos serão professores de outros jovens/alunos cada vez mais imersos no mundo tecnológico." (p.63).

No estudo ora apresentado, a utilização da tecnologia computacional figurou como um elemento da atividade de ensino do professor, que teve por base a necessidade de introduzi-la em sua atividade de planejamento como um artefato mediador do objetivo a ser alcançado na aprendizagem do aluno.

Como afirmado anteriormente, a utilização da tecnologia computacional na formação do professor de matemática tem sido discutida no Brasil por vários pesquisadores. Uma destas investigações foi realizada no âmbito da graduação 
e formação de professores de matemática por Barreto et al. (2006) que, ao analisarem o estado de conhecimento em educação e tecnologia no período entre 1996 e 2002, depararam-se com a "ausência de recursos alocados na formação inicial presencial, impedindo que os professores formados tenham uma história de apropriação das TIC e, em alguns casos, sequer de acesso a elas." (p.39).

O estudo aponta ser imprescindível que os futuros professores tenham espaços para refletir sobre a prática que desejam adotar no futuro, revejam suas posturas e busquem identificação destas com suas possíveis convicções teóricas, a fim de repensar a educação e o ensino da matemática.

$\mathrm{Na}$ proposta em questão, este espaço foi propiciado por meio do PIPE da disciplina Informática e Ensino, mediante análise e planejamento de atividades computacionais de aprendizagem organizadas pelos licenciandos para seus futuros alunos, de modo que tivessem um motivo para mobilizar suas ações para aprender. No entanto, a disciplina, campo da pesquisa, será melhor explicitada no item intitulado "A disciplina Informática e Ensino e seus protagonistas".

Em consonância com essa abordagem, Souza (2001) discute que a formação

[...] dos professores para o uso das novas tecnologias de informação e comunicação implica um redimensionamento do papel que o professor deverá desempenhar na formação dos seus alunos. É, de fato, um desafio, porque significa introduzir mudanças no ensino aprendizagem e, ainda, nos modos de estruturação e funcionamento das escolas e universidades e de suas relações com o meio educativo (p.81).

A pesquisa de Bovo (2004) considera relevante investir na formação de professores para que haja uma consolidação do uso da informática na escola, e tal importância é reconhecida pelos idealizadores de programas governamentais. Estes consideram a formação do professor uma de suas principais ações e condição para o sucesso de tais programas. No entanto, esta mesma autora afirma que "os computadores têm sido pouco utilizados pelos professores, os quais se sentem despreparados para usufruir os recursos computacionais na sala de aula." (p.4).

A formação docente, inicial ou continuada, ao atentar para as tendências educacionais atuais, que se preocupam com estudantes que realizam diversas atividades ao mesmo tempo - ouvem músicas, comem doces e pipocas, jogam videogames, baixam músicas via internet, participam de bate-papos, falam ao telefone, navegam por site -, deve preocupar-se em propiciar subsídios para formar autores, e não meros consumidores/usuários de tecnologias. (SILVA, 2005).

Freitas (2008) analisa as possibilidades e as contribuições da inserção de ambientes de aprendizagem colaborativo e de comunicação virtual em cursos de formação inicial de professores em disciplina presencial no curso de Matemática, utilizando a plataforma eproinfo. Os dados apontam ser a interação escrita em ambiente virtual incentivadora de reflexões que podem contribuir para a formação do professor.

Cardim (2008) realizou um estudo sobre o uso de ambientes computacionais de geometria dinâmica na formação inicial do professor de matemática como um espaço para a produção do saber matemático, em particular, saberes sobre geometria. A pesquisa evidenciou que os sujeitos deram indícios de reflexões sobre a incorporação de softwares de geometria dinâmica à prática docente $\mathrm{e}$ sobre suas possibilidades na construção do saber, incorporando-os em sua prática no momento de estágio.

Miskulin (2003, 2006) explora e discute as possibilidades didático-pedagógicas de ambientes computacionais (presencial e virtual) na formação de professores de matemática numa perspectiva colaborativa. Nesses estudos a autora também tece considerações teórico-metodológicas a respeito da introdução, da disseminação e da utilização da tecnologia em contextos educacionais. A autora afirma que caberia

[...] aos professores-pesquisadores proporcionar contextos favoráveis para que a energia criativa do educando aflorasse e, conseqüentemente, se processasse por meio de novas formas de conhecimento $e$ de compreensão, que possibilitassem ao indivíduo em formação a construção de um conhecimento condizente com a modernidade, na qual a tecnologia desempenha uma função extremamente importante. (MISKULIN, 2003, p.227).

Ainda a autora pondera ser

[...] imprescindivel repensar e

Horizontes, v. 32, n. 2, p. 123-134, jan./jun.2014 
redimensionar a própria concepção de professor e também a constituição dos cursos de formação de professores, os quais devem propiciar aos licenciandos conhecimentos e ações condizentes com as novas tendências educacionais que se estabelecem com os avanços da ciência e da tecnologia. (MISKULIN, 2006, p.158).

As idéias desta autora oferecem elementos para fundamentar a importância de se oferecer, em cursos de formação inicial docente, situações nas quais os graduandos possam explorar ambientes computacionais, vivenciar atividades em tais ambientes e até mesmo produzir atividades computacionais para seus futuros alunos.

Essa ação formativa poderá propiciar ao futuro professor condições de atuar no ensino - de matemática, como o caso em questão — de forma condizente com as novas tendências educacionais e computacionais.

Lessard e Tardif (2008) julgam que os docentes devem aprender a utilizar as TIC para fins pedagógicos, pois estes recursos "podem transformar o papel docente, deslocando o seu centro, da transmissão dos conhecimentos para a assimilação e a incorporação destes pelos alunos, cada vez mais competentes para realizar de maneira autônoma tarefas e aprendizagens complexas." (p.268).

No estudo elucidado neste artigo, foram oferecidos aos protagonistas situações de produção, pesquisa e interação social, em que fosse possível relacionar conhecimentos matemáticos a formas de representá-los em ambientes computacionais. Nessas situações, o planejamento de cada ação a ser operacionalizada fez-se necessário, constituindo-se elemento didático de formação do futuro professor de matemática.

\section{O caminhar: aspectos metodológicos da pesquisa}

Levando em conta a riqueza e complexidade da proposta, o estudo em questão fez parte de uma pesquisa em que o nascimento das principais ideias que a nortearam teve suas sementes plantadas durante as reflexões realizadas em estudos anteriores (MARCO, 2004; 2009). Durante experiências das autoras com a formação do professor, tanto inicial quando continuada, evidenciou-se dificuldades de professores e graduandos em definir conceitos matemáticos. $\mathrm{Na}$ maioria das vezes, os professores/alunos participantes dos cursos descreviam "como calcular", "como aplicar uma fórmula", mas não conseguiam definir conceitualmente um tema matemático.

O caminho percorrido com a formação de professores e de futuros professores, a dificuldade, a "não-habilidade" com computadores e softwares foi outro aspecto considerados instigantes na busca de aliar atividades de ensino de matemática a ambientes computacionais para o ensino da disciplina inerente ao estudo em questão.

A realização dessa proposta concretizou-se mediante a oportunidade de ministrar a disciplina Informática e Ensino no curso de Matemática da Universidade Federal de Uberlândia (MG).

Desta forma, tinha-se na sala de aula da disciplina Informática e Ensino o campo de investigação, considerada como um "ambiente natural" da formação inicial docente dos licenciandos em matemática, aproximando assim das características de uma pesquisa de enfoque qualitativo que, segundo Bogdan e Biklen (1994),

\section{[...] a fonte direta de dados é o ambiente natural, constituído o investigador o instrumento principal. [...]. Os dados são recolhidos em situação e complementados pela informação que se obtém através do contato direto. Além do mais, os materiais registrados mecanicamente são revistos na sua totalidade pelo investigador, sendo o entendimento que este tem deles o instrumento-chave de análise. (p.47).}

Dada a natureza qualitativa da questão de investigação, optou-se por realizar uma pesquisa qualitativa de intervenção com análise interpretativa das enunciações dos sujeitos durante o processo de vivenciar atividades de ensino e produzir atividades computacionais de ensino de matemática para alunos do Ensino Fundamental ou Médio. A preocupação em observar e analisar o processo, e não simplesmente os resultados ou produtos (BOGDAN; BIKLEN, 1994), é outra característica que define $\mathrm{o}$ aspecto qualitativo desta pesquisa.

$\mathrm{Na}$ pesquisa em educação matemática, Fiorentini e Lorenzato (2006, p.110) destacam que a abordagem qualitativa "busca investigar e interpretar o caso como um todo orgânico, uma unidade em ação com dinâmica própria, mas que guarda forte relação com seu entorno e contexto sociocultural".

Em busca de procedimentos éticos na 
pesquisa em educação matemática, esta pesquisa procurou contemplar alguns princípios e cuidados sugeridos por Fiorentini e Lorenzato (2006), tais como: consentimento dos envolvidos; preservação da identidade e da integridade dos envolvidos; mínima interferência do pesquisador no ambiente; e cuidados na divulgação dos dados.

Para o desenvolvimento das atividades foi escolhida como metodologia de aula propor situações-problema envolvendo os conceitos de volume de paralelepípedo, números inteiros e função. Para cada atividade proposta estabeleceu-se mediações no sentido de garantir o movimento indivíduo-coletivo das soluções apresentadas.

A proposta convidava os licenciandos a aceitar o desafio de produzir uma atividade computacional de ensino para futuros alunos de Ensino Fundamental ou Médio, a partir dos elementos que considerassem relevantes em uma das atividades de ensino que haviam vivenciado na disciplina. O interesse dos futuros professores era evidente quando se observava o envolvimento de cada um com a perspectiva de vincular os novos referenciais teóricos à possibilidade de produzir, em pequenos grupos, propostas de ensino adequadas à realidade escolar na qual futuramente poderiam ser inseridos e que, de alguma forma, já conheciam por meio dos estágios realizados em semestres anteriores.

A produção de atividades computacionais de ensino foi o que norteou a segunda parte do estudo. Os licenciandos escolheram um conceito matemático com o qual gostariam de trabalhar com futuros alunos do Ensino Fundamental ou Médio. Para o desenvolvimento das atividades, os alunos dispuseram de duas horas-aula semanais para que fosse possível organizar o trabalho, elegendo conteúdo, objetivos, softwares, ações e operações para a produção da atividade pretendida. Estas duas horas-aula semanais, totalizando 30 horas-aula durante o semestre, compuseram a parte da carga horária obrigatória da disciplina Informática e Ensino, sendo integrantes do Projeto Integrado de Prática Educativa (PIPE).

Ao final da disciplina, houve momentos de socialização, entre os licenciandos, das atividades computacionais de ensino produzidas pelos grupos e a troca de sugestões, por parte da professora e de colegas, com o intuito de aprimorar as atividades desenvolvidas.

A vivência de atividades de ensino caracterizou-se como uma experiência importante para os licenciandos, pois, por meio desta, os futuros professores puderam perceber o motivo de possíveis dificuldades que alunos do Ensino Fundamental ou Médio devido à não-compreensão de conceitos matemáticos.

\section{A disciplina Informática e Ensino e seus protagonistas}

O curso de Matemática da Universidade Federal de Uberlândia foi criado há 46 anos, e, atualmente conta com três modalidades: Licenciatura, Bacharelado (presenciais) e Licenciatura na modalidade a distância no âmbito do Plano Nacional de Formação de Professores da Educação Básica - PARFOR ${ }^{4}$.

Atualmente o curso presencial, alvo de nosso estudo, funciona em período integral, com regime acadêmico semestral e duração de oito semestres, totalizando 3.145 horas. Desse total, 2.765 horas são de componentes obrigatórios e 380 de componentes de escolha do aluno (disciplinas optativas).

A disciplina Informática e Ensino faz parte das disciplinas obrigatórias do segundo semestre de curso e foi introduzida no currículo do curso de Matemática com o objetivo de atender à necessidade de formação de professores para utilização de recursos tecnológicos no contexto de ensino e aprendizagem. Essa inserção considerou também a Resolução CNE/CP No.1, de 18/02/2002, do CNEducação, que institui Diretrizes Curriculares Nacionais para a Formação de Professores da Educação Básica, em cursos de Licenciatura Plena.

A referida disciplina tem como objetivos investigar novas tecnologias aplicadas ao ensino de matemática; explorar regularidades e testar conjecturas associadas a conceitos matemáticos; provocar a mudança de postura didáticometodológica do futuro professor diante das ferramentas tecnológicas de apoio ao ensino; discutir as potencialidades e as limitações de softwares na produção de atividades computacionais de ensino com os licenciandos; promover debates/reflexões acerca das influências de aplicativos computacionais na dinâmica da aula de matemática; vivenciar a execução de projetosmodelo de planejamento de aulas em ambiente informatizado.

Nas 90 horas-aula de curso distribuídas em 6 horas-aulas semanais, o projeto de pesquisa que ora se desenvolvia, o planejamento e o desencadeamento de ações colaboraram para que acontecessem discussões a partir da leitura de textos 
relacionados às possibilidades e às potencialidades do uso de novas tecnologias no ensino de matemática presencial e virtual com os alunos; exploração de ambientes computacionais e discussão de suas potencialidades e limites pedagógicos; construção de Webquests ${ }^{5}$; vivência e exploração de atividades de ensino de matemática; produção em grupos, pelos graduandos, de atividades computacionais de ensino que possibilitem o desenvolvimento de conteúdos matemáticos por alunos do Ensino Fundamental ou Médio; escrita de portfólios; apresentação, no grupo de graduandos, das atividades computacionais de ensino produzidas pelos pequenos grupos.

Deste breve relato pode-se notar que a maior parte do tempo das aulas transcorreu com atividades práticas realizadas pelos graduandos, tanto em sala de aula como no Laboratório de Informática da Universidade, tendo a professorapesquisadora como mediadora do trabalho de todos os grupos. O Laboratório de Informática no qual foram desenvolvidas as aulas era composto por 25 computadores e, por esse motivo, nos momentos de exploração dos ambientes computacionais alguns alunos trabalharam em duplas e/ou trios e outros, individualmente.

$\mathrm{Na}$ disciplina Informática e Ensino utilizouse o yahoo groups ${ }^{6}$ para servir como meio de comunicação entre professora-pesquisadora e alunos e como apoio às atividades presenciais. Toda informação e todos os textos teóricos inerentes ao trabalho e ao conteúdo a ser desenvolvido foram disponibilizados naquele ambiente virtual. Tal ambiente foi utilizado também como um espaço complementar para continuidade de discussões que ocorriam na sala de aula.

A dinâmica da disciplina abordou o desenvolvimento de ações que envolviam integrar o sujeito ao movimento conceitual, devendo o aluno, em um primeiro momento, pensar individualmente sobre a situação encontrada, para, em seguida, discutir as sínteses elaboradas em um grupo de trabalho. Este grupo, por sua vez, elabora uma síntese a partir das reflexões de todos os seus membros e, então, realizava-se uma discussão com o grupo-classe para encontrar uma possível solução ou a solução mais adequada para a situação (LANNER DE MOURA et al., 2003).

Como parte da dinâmica da disciplina, fomentou-se discussão e reflexão sobre a bibliografia sugerida na ementa do curso e cada aluno foi orientado a elaborar mapas conceituais ${ }^{7}$ dos textos teóricos, relacionando-os com: a) inserção de novas tecnologias em ambiente escolar e seus reflexos no currículo de matemática dos Ensinos Fundamental e Médio e nos cursos de formação de professores, b) softwares educacionais: critérios de usabilidade e avaliações técnicas; c) calculadoras e multimídia em ambiente escolar; d) interlocuções realizadas em sala de aula.

Além das atividades anteriormente citadas, como trabalho de final de disciplina, os alunos foram desafiados a produzir, em grupos de cinco ou seis pessoas, atividades computacionais de ensino de matemática, partindo das atividades de ensino vivenciadas e exploradas em sala de aula e das discussões e das explorações de ambientes computacionais utilizadas no ensino de matemática. Tais atividades deveriam contemplar um conceito matemático e uma atividade a ser desenvolvida pelo aluno do Ensino Fundamental ou Médio em ambiente computacional, com o objetivo de levá-lo a compreender tal conceito significativamente.

Os protagonistas da pesquisa eram alunos do curso de Licenciatura em Matemática e estavam realizando estágios em escolas. Este critério de escolha teve como norte a compreensão de que os estagiários estando inseridos no movimento de uma sala de aula e, como tal, tendem a olhar para as situações pedagógicas de modo diferente daqueles alunos que ainda não estão em período de estágio. Esse olhar pode permitir que o futuro professor, além de considerar fatos visíveis, (re)pense a complexidade que a prática docente envolve (CARDIM, 2008).

\section{Conhecendo uma atividade}

Para este artigo, apresentamos uma das atividades produzidas por um dos grupos envolvidos na pesquisa, que abordou as idéias iniciais de função utilizando o software Cabri Géomètre II.

Para a produção desta atividade o grupo em questão (G3) teve como objetivo:

Propor uma situação na qual o aluno do Ensino Médio possa compreender o conceito de função como um movimento regular; levá-lo a explorar o software Cabri Géomètre II para resolver problemas e desenvolver a experimentação ou $a$ modelagem matemática de problemas do mundo real; e promover a compreensão, a interpretação e a utilização de representações matemáticas (tabelas, gráficos, expressões, equações, símbolos) 
(Relatório Final-set/06-G3).

Pode-se inferir que este grupo percebeu a importância de se entender o conceito de função como uma idéia matemática ligada ao aspecto fluente da realidade, ou seja, ao movimento e, especificamente, à regularidade do movimento. Para fundamentar esta idéia, recorremos à Caraça (2000) que ao definir o conceito de função alega que este conceito aparece "no campo matemático, como o instrumento próprio para o estudo das leis". (p.121).

Para operacionalizar os objetivos propostos, o grupo produziu a atividade computacional de ensino que foi denominada "Aprendendo função com o auxílio do software Cabri Géomètre II" (Figura 6).

Percebemos a importância da visualização do aluno de movimento regular no estudo de funções de $1^{o}$ grau e acreditamos que as atividades de ensino vivenciadas sobre este tema nos proporcionaram compreender significativamente o conceito de função (Relatório Final-set/06-G3).

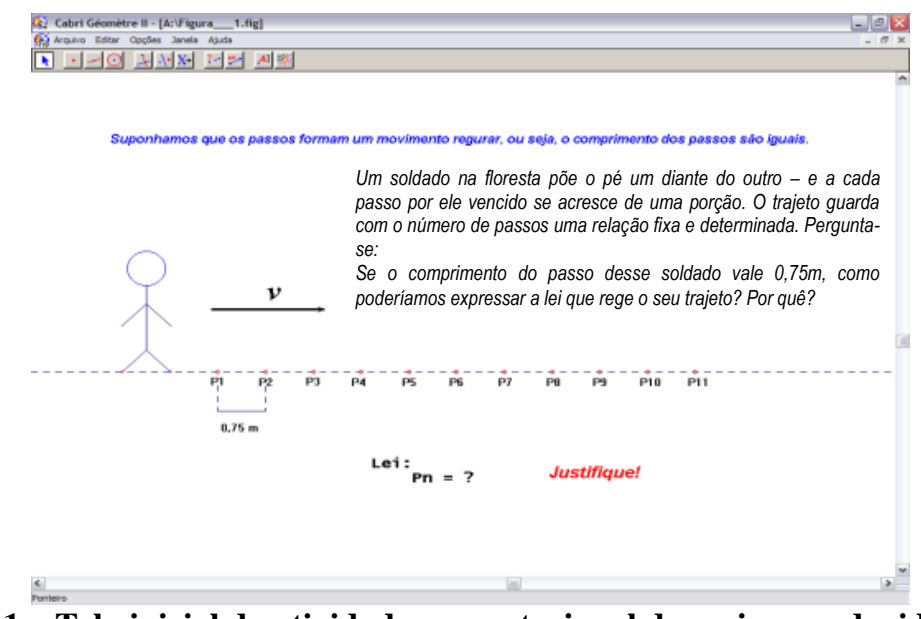

Fig. 1 - Tela inicial da atividade computacional de ensino produzida pelo G3

Inferimos deste registro que estes alunos utilizaram a idéia de movimento regular discutido na referida atividade como o aspecto didáticopedagógico que possa vir a "convidar" os alunos do Ensino Médio para se envolverem na atividade produzida (Figura 6). Cabe destacar também que o registro acima pode estar sustentado pela crença de que a linguagem visual, a imagem, pode ser um facilitador para a aprendizagem mais do que apenas a linguagem oral e escrita. Não há dúvida que o uso do computador pode ser um auxiliar para se ensinar conceitos matemáticos, como no caso desta pesquisa, o conceito de função.

Com ações projetadas para propiciar um contexto desafiador e instigante para o aluno do Ensino Médio, o G3, utilizando ainda a ideia de movimento regular, propôs as seguintes questões (Figuras 7a, 7b):

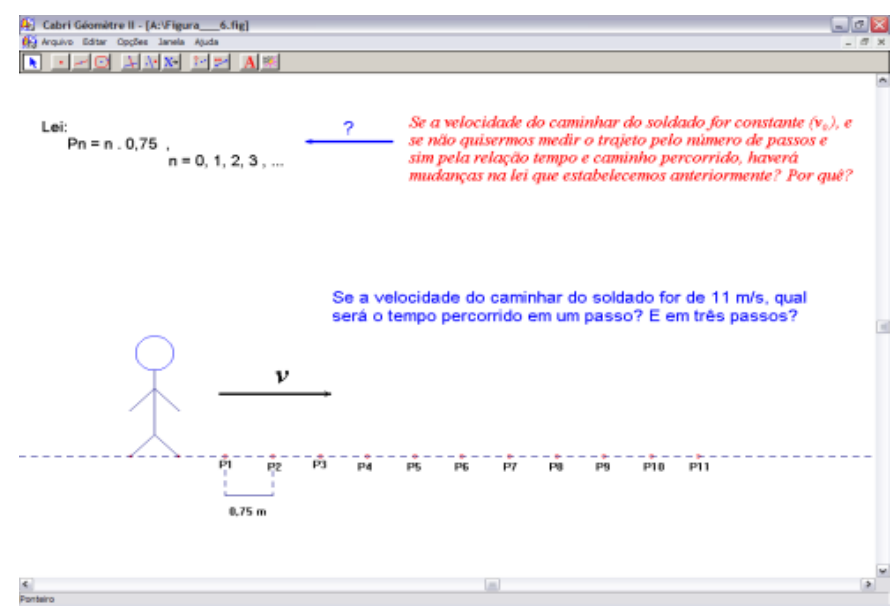

Fig. 2a - Situação-problema 1 elaborada pelo G3 


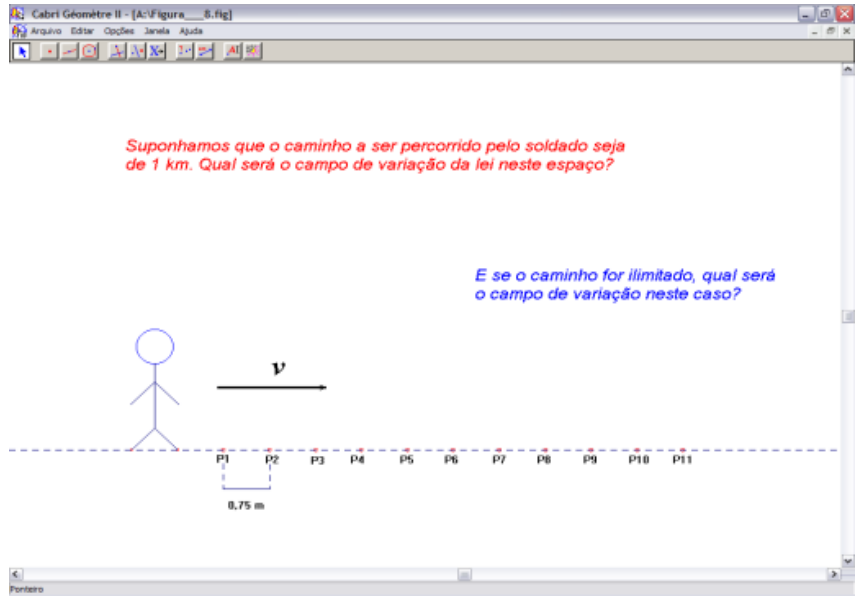

Fig. 2b - Situação-problema 2 elaborada pelo G3

A idéia de movimento é o grande diferencial entre o ambiente computacional Cabri Géomètre II e a mídia tradicional com lápis e papel. Esse diferencial pode permitir ao professor desmistificar determinados conceitos matemáticos que, na maioria das vezes, são complicados para o entendimento do aluno (KAMPFF, MACHADO, CAVEDINI, 2004).

Por meio da utilização da ferramenta tecnológica, percebeu-se a possibilidade de "outro modo de representação do conhecimento matemático, diante da potencialidade da visualização e movimentação que ela possibilita" (CARDIM, 2008, p.124) de forma dinâmica.

No momento da produção da atividade computacional, parece que sentiram a necessidade de organizar-se de modo a distribuir ações entre eles; buscar maiores conhecimentos teóricos para o conteúdo matemático que pretendiam abordar nas atividades; e organizar todas as ideias sugeridas pelos componentes do grupo, de modo a atingir os objetivos a que se propunham, como se depreende da reflexão que segue:

Como produzir uma atividade de ensino interativa na máquina? De que forma poderemos construir isso? Porque, numa atividade de ensino, é preciso estabelecer metas e objetivos bem definidos e, além disso, ela precisa ser avaliada permanentemente. $O$ professor deve fazer intervenções para que o aluno aprenda. Então, como iremos proporcionar isso na atividade de ensino a ser desenvolvida? Pensar nisso foi muito importante porque estimulou uma discussão entre o grupo, respeitando, é claro, as diferentes opiniões. Aos poucos fomos percebendo que existia uma barreira entre nossas idéias e a máquina, porque nem tudo conseguiríamos transferir, ou até mesmo implementar (RFset/06-G2).

Do ponto de vista da formação inicial do aluno para a docência, a implicação didática presente nesta fala diz respeito ao entendimento que os licenciandos adquiriram sobre a necessidade e a importância do conhecimento da gênese de um conceito e do planejamento significativo para o professor; para que ele consiga mobilizar seus alunos para uma aprendizagem efetiva.

A máquina e o ambiente computacional escolhido por cada um dos grupos puderam potencializar o pensamento dos protagonistas, liberando-os para a atividade de planejamento e criação, para a atividade de produzir situações que instiguem e desafiem seus futuros alunos. Além disso, a exploração dinâmica de representações e o controle de uma sequência de ações podem permitir a criação de relações dinâmicas de grande riqueza conceitual (AZINIAN, 1998), tanto para os protagonistas quanto para seus futuros alunos.

\section{Preâmbulo Conclusivo}

A proposta apresentada, posteriormente pôde ser resgatada para (re)elaboração e síntese por ocasião do Seminário de Prática Educativa - SPE em semestres subsequentes. $\mathrm{O}$ reviver, por vezes angustiantes ao buscar contemplar com sucesso o desafio assumido, tornou os momentos de socialização com professores da rede municipal de ensino da cidade de Uberlândia, participantes do SPE, um rico movimento de formação continuada em que as experiências compartilhadas puderam ser aprimoradas e iluminadas com as contribuições do 
olhar dos mais experientes com a prática de ensino e aprendizagem em matemática.

A complexidade da proposta inerente ao projeto pedagógico do curso ficou evidente, porém verificou-se que as possibilidades e potencialidades podem superar as dificuldades quando se tem a clareza do objetivo a ser alcançado.

A atribuição de novas imagens, novos significados para conceitos matemáticos que os licenciandos puderam elaborar ao produzir a atividade computacional leva-nos a inferir que eles perceberam a diferença entre o conceito de função e o modo de executar o procedimento de cálculo das raízes de uma função e parecem querer levar isso para seus futuros alunos. Nas falas e registros dos alunos do grupo envolvido, pode-se perceber que se referem tanto aos ganhos relativos ao aprofundamento conceitual de função quanto ao saber ensinar tal conceito. Tais inferências decorrem de acreditarmos que o futuro professor aprende participando de atividades que tenham a orientação do formador de professores e atribui "significado à atividade que está desenvolvendo, tendo como referência seu conhecimento e crenças prévias" (GARCÍA BLANCO, 2003, p.67).

$\mathrm{Na}$ pesquisa, ficou evidente também que o envolvimento do professor responsável pelo componente curricular agregado ao PIPE é fundamental, em especial, pela necessidade de se planejar as dinâmicas detalhadas e específicas que deverão ser realizadas nos momentos não presenciais da disciplina.

\section{Notas}

1 Este projeto busca desenvolver ao longo do curso de formação de professores de matemática, atividades teóricas e práticas que articulem as disciplinas de formação específica e pedagógica.

2 Beatriz D'Ambrósio (1993); Cooney (1994); Hargreaves (1998); Marcelo Garcia (1998, 1999); Ponte (1998); Fiorentini et al. (2002); Mizukami et al (2002); Ponte, Oliveira e Varandas (2003); Guimarães (2004); Sousa (2004); Fiorentini (2004); Freitas (2006); Gama (2007); Prado (2008); Garcia Blanco (2003), entre outros.

3 Lanner de Moura, Miskulin e Melo (2000); Cláudio e Cunha (2001); Bonilla (2002); Ponte, Oliveira e Varandas (2003); Barcelos (2004); Barreto et al. (2006); Silva (2005, 2006); Silva e Fernandes (2007); Cardim (2008); Freitas (2008), entre outros.

$4<$ http://www.capes.gov.br/educacao- basica/parfor>. Este curso teve seu início no primeiro semestre de 2013.

5 Do inglês, procura ou busca orientada na Web. É uma metodologia de pesquisa orientada, proposta por Bernie Dodge em 1995, com fundamento em aprendizagem cooperativa e processos investigativos na construção do saber; os recursos utilizados são provenientes da Internet. Informações, acesse <www.webquest.futuro.usp.br>.

$6 \mathrm{O}$ leitor que desconhecer este recurso pode buscar informações em <http://br.groups.yahoo.com>.

7 Por mapa conceitual, entende-se uma representação visual de um tema; uma estratégia de estudo, de aprendizagem e de avaliação. Ele deve conter o conceito central, conceitos secundários em estudo e exemplos. Pode ser usado no início, durante o processo de exploração de temas e também ao final desta e antes da avaliação formal ou mesmo como avaliação. (NOVAK, J.; GOWIN, B. Aprender a aprender. Lisboa: Plátano Edições Técnicas, 1999). É importante lembrar que um mapa conceitual pode ter diversas interpretações, pois se refere a um entendimento individual sobre um tema.

\section{Referências}

BARRETO, Raquel Goulart; GUIMARÃES, Glaucia Campos, MAGALHÃES, Ligia Karam Corrêa de; LEHER, Elizabeth Menezes Teixeira E. M. T. As tecnologias da informação e da comunicação na formação de professores. Revista Brasileira de Educação, v. 11, n. 31, p. 31-42, 2006.

BOGDAN, Robert C. e BIKLEN, Sari Knopp. Investigação qualitativa em Educação. Porto, Portugal: Porto Editora, 1994.

BOVO, Audria Alessandra. Formação continuada de professores de matemática para o uso da informática na escola: tensões entre proposta e implementação. Dissertação (Mestrado em Educação Matemática) - Instituto de Geociências e Ciências Exatas, Universidade Estadual de São Paulo, Rio Claro, SP, 2004.

BRASIL. Ministério da Educação. Secretaria de Ensino Fundamental. Referenciais para a formação de professores. Brasília: MEC/SEF, Brasília, 1997. 
CARDIM, Viviane Rocha Costa. Saberes sobre a docência na formação inicial de professores de matemática. Dissertação (Mestrado em Educação) - Universidade São Francisco, Itatiba, 2008, 185p.

FIORENTINI, Dario; LORENZATO, Sergio. Investigação em educação matemática: percursos teóricos e metodológicos. Campinas, SP: Autores Associados, 2006.

FREITAS, Maria Teresa Menezes. Ambiente virtual de aprendizagem no ensino presencial de formação de professores de matemática. In: ENDIPE ENCONTRO NACIONAL DE DIDÁTICA E PRÁTICA DE ENSINO, 14., 2008, Porto Alegre, RS. Anais...

GARCÍA BLANCO, Maria Mercedes. A formação inicial de professores de matemática: fundamentos para a definição de um curriculum. In: FIORENTINI, D. (Org.). Formação de professores de matemática: explorando novos caminhos com outros olhares. Campinas, SP: Mercado de Letras, 2003.

GAUTHIER, Clermont et al. Por uma teoria da pedagogia: pesquisas contemporâneas sobre o saber docente. 2 ed. Ijuí: Ed. Ijuí, 2006.

KAMPFF, Adriana Justin Cerveira; MACHADO, José Carlos; CAVEDINI, Patrícia. Novas tecnologias e Educação Matemática. In: CONGRESSO DA SOCIEDADE BRASILEIRA DE COMPUTAÇÃO, 23., 2004, Bahia. Anais...

LANNER DE MOURA, Anna Regina et al. Movimento conceitual em sala de aula. In: CIAEM - CONFERÊNCIA INTERAMERICANA DE EDUCACIÓN MATEMÁTICA, 11., 2003, Blumenau, SC. Anais... 2003.

LANNER DE MOURA, Anna Regina; MISKULIN, Rosana Giaretta Sguerra; MELO, Gilberto Francisco Alves de. A tecnologia computacional como potencializadora da aprendizagem compartilhada do conceito matemático. In: MATOS, João Filipe; FERNANDES, Elsa. (Org.). Investigação em educação matemática: perspectivas e problemas. Lisboa: Associação de Professores de Matemática, 2000. pp.145-152.

LESSARD, Claude; TARDIF, Maurice. As transformações atuais do ensino: três cenários possíveis na evolução da profissão professor? In: TARDIF, Maurice; LESSARD, Claude (Org). $O$ ofício de professor: história, perspectivas e desafios internacionais. Tradução Lucy Magalhães. Petrópolis: Vozes, 2008.

MARCELO GARCÍA, Carlos. Formação de professores: para uma mudança educativa. Porto: Porto Editora, 1999.

MARCO, Fabiana Fiorezi de. Atividades computacionais de ensino na formação inicial do professor de matemática. Tese (Doutorado em Educação: Educação Matemática) — Faculdade de Educação, Universidade Estadual de Campinas, Campinas, SP, 2009. 223p.

Estudo dos processos de resolução de problema mediante a construção de jogos computacionais de matemática no ensino fundamental. Dissertação (Mestrado em Educação: Educação Matemática) - Faculdade de Educação, Universidade Estadual de Campinas, Campinas, SP, 2004. 141p.

MISKULIN, Rosana Giaretta Sguerra. As possibilidades didático-pedagógicas de ambientes computacionais na formação colaborativa de professores de matemática. In: FIORENTINI, D. (Org.). Formação de professores de matemática: explorando novos caminhos com outros olhares. Campinas, SP: Mercado de Letras, 2003.

. As potencialidades didático-pedagógicas de um laboratório em educação matemática mediado pelas TICs na formação de professores. In: LORENZATO, S. (Org.). O laboratório de ensino de matemática na formação de professores. Campinas, SP: Autores Associados, 2006.

SILVA, Rejane Maria Ghisolfi. Formação docente: outra lógica frente aos desafios da informatização. In: FONSECA, Selva Guimarães; BARAÚNA, Silvana Malusá; MIRANDA, Arlete Bertoldo. (Org). $O$ uno e o diverso em educação escolar. Uberlândia: EDUFU: FAPEMIG, 2005.

SILVA, Rejane Maria Ghisolfi; FERNANDES, Márcia Aparecida. Produção e desenvolvimento de objetos de aprendizagem para o ensino de química: implicações na formação docente. In: LOPES, Carlos Roberto; FERNANDES, Márcia Aparecida. (Org.). Informática na educação: elaboração de 
objetos de aprendizagem. Uberlândia: EDUFU, 2007.

SOUZA, Maria José Araújo. Informática educativa na Educação Matemática: Estudo de geometria no ambiente do software Cabri-Géomètre. Dissertação (Mestrado) - Universidade Federal do Ceará, CE,
2001.

Projeto Pedagógico do Curso de Matemática da Universidade Federal de Uberlândia. 2005. In: http://www.famat.ufu.br/sites/famat.ufu.br/files/Ane xos/Bookpage/MA_ProjetoPedagogico.pdf.

\section{Sobre as autoras}

Fabiana Fiorezi de Marco é doutora em Educação Matemática pela Universidade Estadual de Campinas e Professora da Faculdade de Matemática da Universidade Federal de Uberlândia.

Maria Teresa Menezes Freitas é doutora em Educação Matemática pela Universidade Estadual de Campinas e Professora da Faculdade de Matemática da Universidade Federal de Uberlândia.

Anna Regina Lanner de Moura é doutora em Educação pela Universidade Estadual de Campinas e Professora da Faculdade de Educação da Universidade Estadual de Campinas.

Artigo recebido em dezembro de 2013

Artigo aprovado em fevereiro de 2014 